(C) B.А. Даньшов

Рязанский государственный медицинский университет им. академика И.П. Павлова, г. Рязань, Российская Федерация

Демографические процессы, происходящие в регионах, существенно влияют на особенности организации и планирования медицинской помощи. Рязанская область относится к староосвоенным регионам России с регрессивным типом воспроизводства населения. Демографическая ситуация в регионе характеризуется низкой рождаемостью и высокой смертностью, что ведет к убыли населения в области. Так, отмечается высокая доля населения старше трудоспособного возраста $(29,8 \%)$, снижение доли трудоспособного населения $(54,7 \%)$ и невысокая доля детей и подростков $(15,5 \%)$. Тем не менее, в период 20142016 гг. наблюдается положительная тенденция увеличения рождаемости, суммарного коэффициента рождаемости (в 2014 г. этот показатель составлял 1,595, к 2016 г. он вырос до $1,703)$ и снижения младенческой смертности (в 2014 г. младенческая она составляла 6,3 умерших на 1000 родившихся, в 2015 г. - 6,2, в 2016 г. - 4,5, что ниже показателя младенческой смертности в Российской Федерации на 25\% и Центральном Федеральном округе на 19,6\%). В этих условиях большое значение придается организации системы оказания медицинской помощи детскому населению. В Рязанской области построена трехуровневая система оказания медицинской помощи детям. Данная система оказания медицинской помощи позволяет осуществить дифференцированный подход к диагностике и лечению в медицинских организациях с учетом структуры учреждения, коечной мощности, уровня оснащения и обеспеченности квалифицированными медицинскими кадрами медицинской организации и снизить младенческую и детскую смертность.

Ключевые слова: организация медиџинской помощи детям, трехуровневая система организащии медицинской помощи, демографические риски.

\title{
ORGANIZATION OF MEDICAL CARE FOR CHILD POPULATION IN THE RYAZAN REGION IN CONDITIONS OF DEMOGRAPHIC RISKS
}

\author{
(C) V.A. Danshov
}

Ryazan State Medical University, Ryazan, Russian Federation

Demographic processes in the regions significantly influence peculiarities of organization and planning of medical care. The Ryazan region is a long-established area of Russia with regressive type of reproduction of the population. Demographic situation in the region is characterized by a low birth rate and a high mortality rate leading to decline in the population. Thus, there is a high share of population older than the working age (29.8\%), reduced share of the population of the working age $(54.7 \%)$ and an insignificant share of children and teenagers (15.5\%). Nevertheless, 
in the period from 2014 to 2016 a positive tendency was noted to increase in birth rate, in the total fertility rate (in 2014 this parameter was 1.595 , by 2016 it increased to 1.703 ), and to reduction in infant mortality (in 2014 it was 6.3 deaths per 1000 births, in 2015 - 6.2, in $2016-4.5$ ) which was 25\% lower than that in Russian Federation and 19\% lower than in the Central Federal Region. In these conditions of high importance is organization of medical care for child population. In the Ryazan region three-level system of rendering medical care for children is introduced. This system permits to realize differentiated approach to diagnostics and treatment in medical organizations taking into account their structure, bed capacity, the level of equipment and provision with medical personnel, and to reduce infant and children mortality.

Keywords: organization of medical care for children, three-level system of organization of medical care, demographic risks.

Одной из основных целей государственной демографической политики в Российской Федерации является увеличение численности населения нашей страны за счет повышения рождаемости, сокращения смертности и увеличения продолжительности жизни россиян. В связи с этим разработка стратегии отечественного здравоохранения осуществляется с учетом демографических рисков. В этом контексте вопросы охраны материнства и детства занимают ведущее место в системе мер по преодолению демографического кризиса.

Важную роль в сохранении здоровья населения играет организация медицинской помощи детям, учитывающая демографические особенности региона. В связи с этим представляется актуальным анализ демографической ситуации Рязанской области для разработки оптимальной модели оказания медицинской помощи с использованием данных Федеральной службы государственной статистики по Рязанской области за 2014-2016 гг. [1,2].

Демографическая ситуация, сложившаяся в Рязанской области, как и во всей России, характеризуется сложными процессами. Рязанская область относится к староосвоенным регионам России с регрессивным типом воспроизводства населения. Демографическая ситуация в регионе характеризуется низкой рождаемостью и высокой смертностью, что ведет к убыли населения в области.

В Рязанской области сформировалась неблагоприятная для социальноэкономического развития региона струк- тура населения. Соотношение населения трудоспособного возраста, младше трудоспособного и старше трудоспособного в 2016 г. составляло $54,7 \%-15,5 \%-29,8 \%$ соответственно. При этом, если динамика доли населения младше трудоспособного возраста имеет положительную динамику: в 2014 г. доля их составляла 14,8\%, в 2015 г. $-15,1 \%$, в 2016 г. $-15,5 \%$, то доля трудоспособного населения - отрицательную (с 57,0\% в 2014 г. до 54,7\% в 2016 г.) при увеличении доли населения старше трудоспособного возраста с 28,5\% в 2014 г. до $29,8 \%$ в 2016 г.).

Так, в 2016 г. число родившихся на 1000 населения в Рязанской области составило 11,3 (в Российской Федерации - 12,9), число умерших на 1000 человек - 16,0 (в Российской Федерации - 12,9), естественная убыль - 4,7. Несмотря на положительную динамику рождаемости в период 2014-2016 гг. с 11,0 до 11,3 родившихся на 1000 населения, остаются высокими показатели смертности населения 16,1 в 2014 г., 15,8 в 2015 г., 16,0 в 2016 г.

В течение последних трех лет в Рязанской области наблюдается увеличение суммарного коэффициента рождаемости (число детей в расчете на одну женщину): если в 2014 г. этот показатель составлял 1,595, то к 2016 г. он вырос до 1,703. Такая тенденция является позитивной в демографической ситуации региона.

Важным демографическим показателем является показатель младенческой смертности. В 2014 г. младенческая смертность в Рязанской области составля- 
ла 6,3 умерших на 1000 родившихся, в 2015 г. - 6,2, в 2016 г. - 4,5, что ниже показателя младенческой смертности в Российской Федерации на $25 \%$ и Центральном Федеральном округе - на 19,6\%.

Во многом это результат планомерной работы сферы здравоохранения и органов государственной власти. Открытие в г. Рязани современного перинатального центра позволило решить ряд проблем в оказания медицинской помощи беременным женщинам и новорожденным, что способствовало снижению младенческой смертности.

Состояние здоровья новорождённых в Рязанской области характеризуется выраженной заболеваемостью. В родильных домах и отделениях по статистическим данным регистрируется 600 заболеваний на 1000 новорождённых. В группе детей первого года жизни зарегистрированная заболеваемость составляет 2900 на 1000 детей, в возрастной группе 0-14 лет - 2702 на 1000 детей, среди подростков - 3002 на 1000 подростков. Отмечается рост заболеваемости у детей, который связан, с одной стороны, с улучшением диагностики и своевременным выявлением патологии, в том числе и во время проведения профилактических осмотров и диспансеризации детей, с другой, объективным ухудшением состояния здоровья детей $[1,3]$.

В Рязанской области активно протекают миграционные процессы. Так, в 2016 году прирост населения региона на 1864 человека произошел за счет мигрантов, в основном из стран СНГ. И, несмотря на то, что миграционные процессы, происходящие в Рязанской области, не оказывали существенного влияния на изменение демографической ситуации в регионе (миграционный прирост лишь частично компенсировал естественную убыль населения - на 32,8\%), но эти процессы увеличивают нагрузку на систему здравоохранения.

Таким образом, происходящие демографические процессы не могут не влиять на особенности организации и ресурсопотребление системы здравоохранения.

В целях сохранения и укрепления здоровья детей и подростков, формирова- ния здорового образа жизни, раннего выявления факторов риска и их индивидуальной коррекции необходимо усилить профилактическое направление, сделать его системным. В 2016 году в Рязанской области профилактическими осмотрами было охвачено 173377 детей (95\% от прикрепленного детского населения). Всем детям при наличии медицинских показателей по результатам диспансеризации было проведено дополнительное обследование, лечение и оздоровительные мероприятия. Охват диспансеризацией пребывающих в стационарных учреждениях детей-сирот и детей, находящихся в трудной жизненной ситуации (2774 ребенка), детей-сирот и детей, оставшихся без попечения родителей, в том числе усыновленных (удочеренных), принятых под опеку (попечительство), в приемную или патронатную семью (1422 ребенка) составил в 2016 году $100 \%$ [2].

Медицинская помощь детям в Рязанской области оказывается в медицинских организациях трех уровней. Трехуровневая система - иерархическая система оказания медицинской помощи, по которой медицинские организации или их подразделения в зависимости от основной или преимущественной деятельности и наделенных функций распределены по трем уровням. Целью трехуровневой системы оказания медицинской помощи детям является своевременное, качественное и в полном объеме оказание медицинской помощи детям Рязанской области. Трехуровневая система организации оказания медицинской помощи интегрирована в существующую систему регионального здравоохранения, с сохранением классификации по видам, условиям и форме оказания медицинской помощи, обеспечивая возможность соблюдения порядков оказания медицинской помощи, выполнение стандартов медицинской помощи, сохранение преемственности и этапности лечебных мероприятий, дальнейшую разработку схемы маршрутизации пациентов при различных заболеваниях и состояниях [4].

Медицинская помощь в зависимости от деятельности, выполняемой медицин- 
скими организациями, распределяется на 3 уровня:

1) первый уровень - оказание преимущественно первичной медико-санитарной, в том числе первичной специализированной медицинской помощи, а также специализированной медицинской помощи и скорой медицинской помощи (в центральных районных больницах, городских, районных, участковых больницах, городских поликлиниках, станциях скорой медицинской помощи).

Медицинские организации первого уровня преимущественно осуществляют комплекс мероприятий, включающий первичную профилактику, раннюю, наиболее распространенную и минимально затратную диагностику, лечение заболеваний и состояний без использования сложных и ресурсоемких методов, медицинскую реабилитацию, паллиативную помощь, формирование здорового образа жизни и санитарно-гигиеническое просвещение населения.

2) второй уровень - оказание преимущественно специализированной (за исключением высокотехнологичной), медицинской помощи в медицинских организациях, имеющих в своей структуре специализированные межмуниципальные (межрайонные) отделения и (или) центры, а также в диспансерах, многопрофильных и специализированных больницах. Медицинские организации второго уровня преимущественно осуществляют комплекс мероприятий, включающий специальную диагностику и лечение заболеваний и состояний с использованием распространенных и отдельных сложных ресурсоемких, но не относящихся к высокотехнологичным видам, методик, а также медицинскую реабилитацию.

3) третий уровень - оказание преимущественно специализированной, в том числе

\section{Литература}

1. Артемьева Г.Б., Гехт И.А. Особенности организации медицинской помощи детям в условиях демографических вызовов // Экономист лечебного учреждения. 2015. №9. С. 3-9.

2. Прилуцкий А.А. О результатах работы системы здравоохранения Рязанской об- высокотехнологичной, медицинской помощи в медицинских организациях, оказывающих высокотехнологичную медицинскую помощь в условиях стационара и дневного стационара. Медицинские организации третьего уровня применяют для диагностики и лечения уникальные сложные и ресурсоемкие методы с научно доказанной эффективностью, относящиеся к высокотехнологичным видам медицинской помощи [5].

Данная система оказания медицинской помощи детям позволяет осуществить дифференцированный подход к диагностике и лечению в медицинских организациях с учетом структуры учреждения, коечной мощности, уровня оснащения и обеспеченности квалифицированными медицинскими кадрами медицинской организации и снизить младенческую и детскую смертность.

\section{Заключение}

Демографические процессы, происходящие в Рязанской области, приводят к неблагоприятной для социально-экономического развития региона структуре населения, характеризующейся высокой долей населения старше трудоспособного возраста $-29,8 \%$, снижением доли трудоспособного населения - 54,7\% и невысокой долей детей и подростков - $15,5 \%$. В этих условиях большое значение придается организации системы оказания медицинской помощи детскому населению. Трехуровневая система оказания медицинской помощи детям позволяет осуществить дифференцированный подход к диагностике и лечению в медицинских организациях с учетом структуры учреждения, коечной мощности, уровня оснащения и обеспеченности квалифицированными медицинскими кадрами медицинской организации, снизить младенческую и детскую смертность, повысить доступность и качество медицинских услуг.

ласти в 2016 году и задачах на 2017 год / Доклад министра здравоохранения Рязанской области на расширенном заседании коллегии министерства здравоохранения Рязанской области. Режим доступа: https://minzdrav.ryazangov.ru/upload/iblock /583/3-doklad-prilutskogo-na-kollegiyuitogi-2016.pdf. 
3. Гехт И.А., Артемьева Г.Б., Пирский Д.А. Постарение населения: демографические, медицинские и экономические аспекты. Самара: Акцент, 2012.

4. Ваганов Н.Н. Роль многопрофильных детских стационаров в современном здравоохранении и снижении младенческой смертности // Роль областных и республиканских детских клинических больниц в стабилизации демографической ситуации: материалы международной научно-практической конференции главных врачей областных, краевых, республиканских, окружных детских больниц Российской Федерации. Рязань, 2015. С. 9-12.

5. Федеральный закон от 21 ноября 2011 г. №323-Ф3 «Об основах охраны здоровья граждан в Российской Федерации». Режим доступа: http://base.garant.ru/57428163/

\section{References}

1. Artemeva GB, Gekht IA .Osobennosti organizatsii meditsinskoi pomoshchi detiam $\mathrm{v}$ usloviiakh demograficheskikh vyzovov. Ekonomist lechebnogo uchrezhdeniia. 2015;9:3-9. (In Russ).

2. Prilutskiy AA. $O$ rezultatakh raboty sistemy zdravookhraneniia Riazanskoi oblasti v 2016 godu i zadachakh na 2017 god. Doklad ministra zdravookhraneniia Riazanskoy oblasti na rasshirennom zasedanii kollegii ministerstva zdravookhraneniia Riazanskoi oblasti. Available at: https://minzdrav.ryazangov.ru/upload/ibloc k/583/3-doklad-prilutskogo-na-kollegiyuitogi-2016.pdf.

3. Gekht IA, Artemeva GB, Pirskiy DA. Postarenie naseleniia demograficheskie meditsinskie $i$ ekonomicheskie aspekty. Samara: Aktsent; 2012. (In Russ).

4. Vaganov NN. Rol mnogoprofilnykh detskikh statsionarov $v$ sovremennom zdravookhranenii $i$ snizhenii mladencheskoi smertnosti Rol oblastnykh $i$ respublikanskikh detskikh klinicheskikh bolnits $v$ stabilizatsii demograficheskoi situatsii. In: Materialy mezhdunarodnoi nauchnoprakticheskoi konferentsii glavnykh vrachei oblastnykh kraevykh respublikanskikh okruzhnykh detskikh bolnits Rossiiskoi Federatsii. Ryazan; 2015. P. 9-12. (In Russ).

5. Federalnyi zakon ot 21 noiabria $2011 \mathrm{~g} \mathrm{~N}$ 323-FZ Ob osnovakh okhrany zdorovia grazhdan v Rossiiskoy Federatsii. Available at: http://base.garant.ru/57428163/

\section{Информация об авторах [Authors Info]}

Даньшов В.А. - магистрант 2 года обучения кафедры общественного здоровья и здравоохранения ФДПО, ФГБОУ ВО РязГМУ Минздрава России, г. Рязань, российская Федерация.

V.A. Danshov - graduate student 2 years of training, Department of public health and health care the faculty of Additional Professional Education, Ryazan State Medical University, Ryazan, Russian Federation.

Цитировать: Даньшов В.А. Об организации медицинской помощи детскому населению в Рязанской области в условиях демографических рисков // Наука молодых (Eruditio Juvenium). 2018. Т. 6, №2. С. 326-330.

To cite this article: Danshov VA. Organization of medical care for child population in the Ryazan region in conditions of demographic risks. Science of the young (Eruditio Juvenium). 2018;6(2):326-30.

Поступила / Received: 08.05.2018

Принята в печать / Accepted: 01.06.2018 